TITLE:

\title{
A NEW REMARKABLE SYNSTYELID, POLYANDROCARPA (EUSYNSTYELA) TRANSVERSALIS N. SP., FROM HAWAII
}

$\operatorname{AUTHOR}(\mathrm{S}):$

Tokioka, Takasi

CITATION:

Tokioka, Takasi. A NEW REMARKABLE SYNSTYELID, POLYANDROCARPA (EUSYNSTYELA) TRANSVERSALIS N. SP., FROM HAWAII. PUBLICATIONS OF THE SETO MARINE BIOLOGICAL LABORATORY 1963, 11(1): 101-104

\section{ISSUE DATE:}

1963-07-20

URL:

http://hdl.handle.net/2433/175324

RIGHT: 


\title{
A NEW REMARKABLE SYNSTYELID, POLYANDROCARPA (EUSYNSTYELA) TRANSVERSALIS N. SP., FROM HAWAII ${ }^{1)}$
}

\author{
TAKASI TOKIOKA
}

Seto Marine Biological Laboratory

With Plate III

While an ascidian sample from Station 3876 of the United States Fisheries Commission Steamer "Albatross" Hawaiian Explorations 1902 was examined, a number of small zooids of an unknown synstyelid were found attached to the surface of Ascidia sydneiensis samea (ОKA), several specimens of this species constituted the sample together with a few individuals of Herdmania momus (SAvigNy). In all about fifty large and small zooids were included. They are oval in shape, up to $4 \mathrm{~mm}$ in length, strongly compressed dorso-ventrally and connected one another by a few thin creeping stolons. Both apertures are apart from each other for a half of the body length and situated each in a similar distance from respective body ends (Plate III, Fig. a). They are usually rounded and opened each on a small prominence. The animal is brownish or reddish brown in colour in a preserved state in alcohol.

The test is very thin, especially on the ventral attachment surface, but tough enough, translucent to transparent and nearly smooth on the surface. A thinner membraneous extension of test is found along the periphery of the attachment side. The mantle is also very thin, especially remarkably on the ventral side. Many small elongate endocarps are scattered over the inner surface of the dorsal half of the body. Atrial tentacles were not observed, this is probably because of a strong contraction.

Branchial sac: The branchial sac is relatively small, not filling the whole body cavity and ending posteriorly approximately at the level of the posterior one third of the body length (Plate III, Fig. b). There are four plications on each side, of which the first (the dorsal-most) and the third are well formed, while the second and the fourth (the ventral-most) are each represented merely by a group of several inner longitudinal vessels. Inner longitudinal vessels are amazingly numerous for such a small body size and any intermediate spaces

1) Contributions from the Seto Marine Biological Laboratory, No. 396.

Publ. Seto Mar. Biol. Lab., XI (1), 1963. (Article 5) 
are practically indiscernible between inner longitudinal vessels. Vessels are arranged as :

$$
\begin{aligned}
& \text { Left side D. } 0 \text { (10) } 0 \text { (4) } 0 \text { (12) } 0 \text { (7) } 0 \mathrm{~V} \text {. } \\
& \text { Right side D. } 0 \text { (12) } 0 \text { (4) } 0 \text { (12) } 0 \text { (7) } 0 \mathrm{~V} \text {. }
\end{aligned}
$$

The most peculiar feature of the present species is found in the shape and arrangement of stigmata (Plate III, Fig. c). In the narrow area along each side of the endostyle and also in the limited anterior part of the area between the third and the fourth (the ventral-most) branchial plications, stigmata are of the usual elliptical shape, longer in the antero-posterior direction and such stigmata are arranged in several transverse rows as each one contains only a few stigmata. Most part of the branchial sac is, however, perforated by a number of relatively large transversely elongate stigmata, each stretching across a few to several inner longitudinal vessels. For such structure and distribution of stigmata, any special differentiation is not seen in the thickness of the transverse vessels. Only eight tentacles were observed clearly; it is not impossible that smaller ones were contracted strongly and thus escaped from the examination. The ciliated groove is a small elliptical opening, slightly longer anteroposteriorly.

Alimentary canal: The intestinal loop traces a simple closed 0-shaped course (Plate III, Figs. $d$ and $e$ ) ; it is about one-fourth as long as the body and situated in an ordinary state of contraction as the pyloric end of the stomach is located at the level of the posterior one-third of the body. The oesophagus is of a moderate length. It is bent sharply, opening to the rear end of the branchial sac and entering the stomach which is situated with its cardiac end posteriorly and the pyloric end anteriorly. The stomach is roughly oval in outline, about half as long as the loop, slightly longer than wide and provided with about six stout longitudinal plications on the surface. A remarkable pyloric coecum is present; it is a little curved. A short hind-stomach, about one third as long as the stomach, is indistinctly discernible. The following part of the intestine is walled with rather thicker tissue till it reaches the level of the pyloric coecum; probably this part represents the middle intestinal portion. The intestine then runs posteriorly towards the cardiac end of the stomach gradually diminishing the thickness, there it turns dorsad and ends at the anus opening just on the left side of the oesophageal opening of the branchial sac and with lips both smoothly thickened. The distal portion of the rectum running in the ventro-dorsal direction along the oesophagus is very short.

Gonad: A series of hermaphroditic gonads along each lateral side of the body wall widely apart from the endostyle. They are up to eight on respective side and often diminish the size towards the ends of the row. Each gonad (Plate III, Fig. $f$ ) is constituted of a single ovary and a testis always consisting 
of two roundish or slightly triangular testicular follicles. The ovary occupies the inner anterior side of the gonad. Ducts are very short.

Remarks: The existence of transversely elongate stigmata in the present specimens reminds us of Berrillia boltenioides Brewin, 1952* from New Zealand waters and Protostyela heterobranchia Millar, 1954** from Scottish waters. However, the present form differs distinctly from the above-mentioned two peculiar species in structures of the branchial sac and the gonad. Rather, structures of these organs conform quite to those found in species of the subgenus Eusynstyela of the genus Polyandrocarpa. If the existence of transversely elongate stigmata is always of a generic significance, then the present form should represent a species of a new genus. In the present form, however, there remain still a few ordinary stigmata along the endostyle. It seems that the reduction of the intermediate spaces between inner longitudinal vessels makes it difficult to hold ordinary stigmata. It is not impossible that transversely elongate stigmata have appeared in this case as a structure adapted to the form having too many inner longitudinal vessels for so small body size. Thus I hesitate to consider the existence of transversely elongate stigmata to be a feature of systematic importance, at least for the present form, and want to treat the form merely as an unsual new species of Eusynstyela. This new species may be accepted as a form showing an intermediate stage in the process of formation of transversely elongate stigmata and may call for the reexamination of the validity of some genera characterized by having transverse stigmata in small bodies.

Before closing the description I want to express my hearty thanks to Dr. F. CHACE of the Division of Marine Invertebrates of the United States National Museum for his kindness in letting me have the chance to examine the present specimens. All the specimens are deposited at the United States National Museum.

* Brewin, B. I. (1952): Ascidians of New Zealand. Part VII. Ascidians from Otago coastal waters. Part II. Transact. Roy. Soc. N. Z., Vol. 79, Parts 3-4, pp. 454-455, Text-fig. 3.

** Millar, R. H. (1954): Protostyela heterobranchia n. gen., n. sp., a styelid ascidian from the Scottish west coast. J. mar. Biol. Ass. U. K., Vol. 33, pp. 677-679, Text-fig. 1. 


\section{EXPLANATION OF PLATE III}

Polyandrocarpa (Eusynstyela) transversalis n. sp.

a-A zooid, dorsal side.

$b$-Ventral side of a mantle body.

$c$-A part of the branchial sac along the endostyle.

$d$-Alimentary canal, ventral side.

$e$-Alimentary canal, dorsal side.

$f-$ A gonad from the right side. 


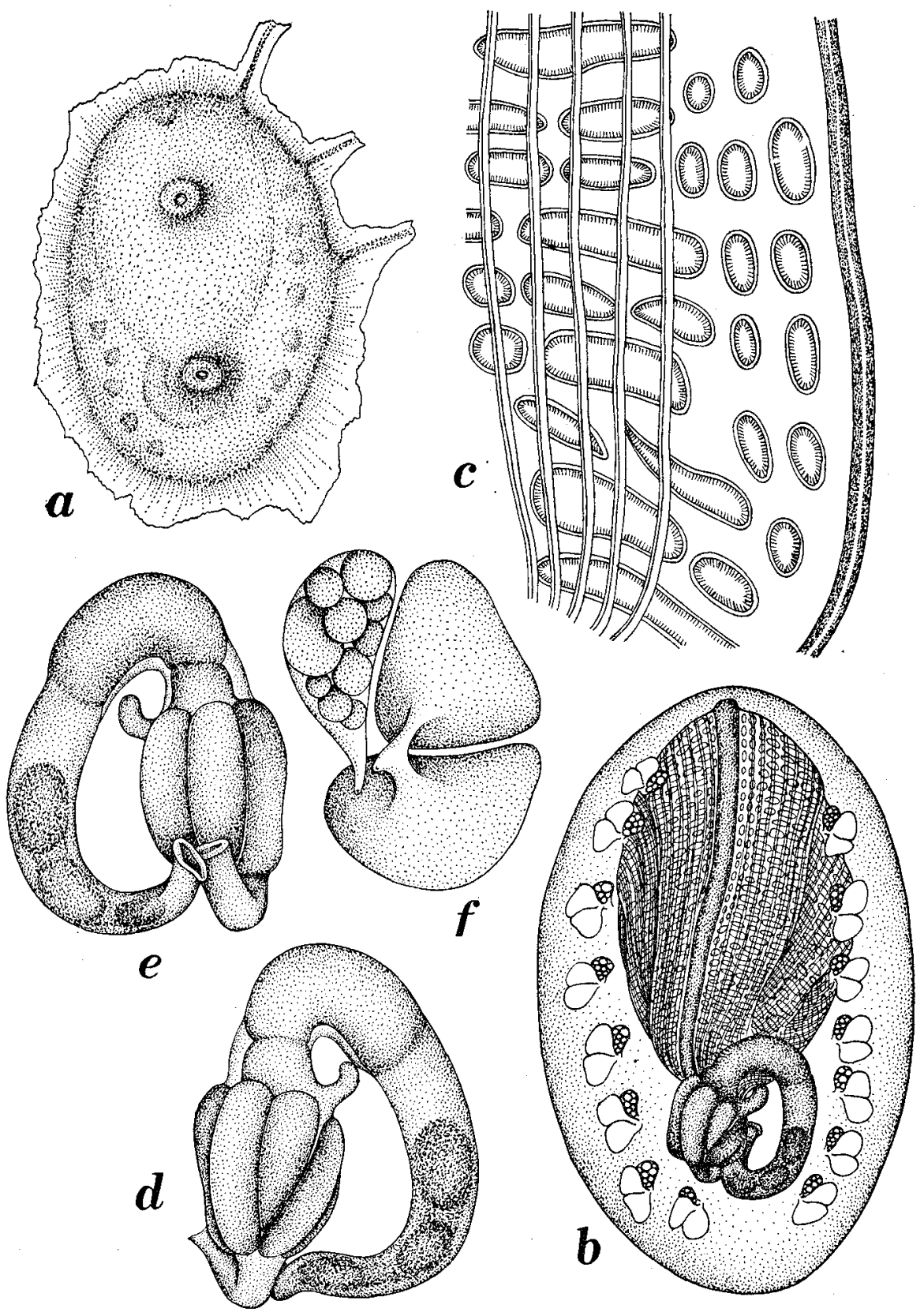

T. Tokioka; A New Remarkable Synstyelid from Hawair. 